\title{
A Contrastive Inquiry into Wh-Interrogatives in English and Nigerian Pidgin
}

\author{
Macaulay Mowarin ${ }^{1} \&$ Akpofure Oduaran ${ }^{1}$ \\ ${ }^{1}$ Department of English and Literary Studies, Delta State University, Abraka - Delta State, Nigeria \\ Correspondence: Macaulay Mowarin, Department of English and Literary Studies, Delta State University, Abraka - \\ Delta State, Nigeria. E-mail: mamowarin@yahoo.co.uk
}

Received: August 6, 2014

Accepted: November 10, 2014

Online Published: December 2, 2014

doi:10.5430/elr.v3n2p90

URL: http://dx.doi.org/10.5430/elr.v3n2p90

\begin{abstract}
This paper undertakes a contrastive inquiry into $w h$-interrogatives in English and Nigerian pidgin based mainly on Chomsky's minimalist program of transformational grammar as the theoretical framework. It is a pedagogical approach to the study of Nigerian pidgin in the Niger Delta region of Nigeria where the language has creolised. The main objectives of the paper are as follows: first, it undertakes an overview of English and Nigerian pidgin and the cross linguistic typological variations of $w h$-questions. Second, evaluates linguistically, the $w h$-interrogatives in English and Nigerian pidgin with focus on $w h$-words and phrases, movement, pied piping and constraints on $w h$-movement in the two languages. The paper also discusses the use of ná and nkợ as $w h$-forms in NP. Finally, the paper examines the learning problems that a competent speaker of Nigerian pidgin will encounter while learning English $w h$-interrogatives as a second language. The importance of contrastive analysis as a panacea to the problem of semi-literary in English in Nigeria's Niger Delta is underscored in this paper.
\end{abstract}

Keywords: Contrastive inquiry, Wh-Interrogatives, Nigerian pidgin

\section{Introduction}

The derivation of interrogatives from kernel sentences is a linguistic universal; what is more, it is a core aspect of syntactic analysis. This paper is a contrastive analysis of $w h$-interrogatives in English and Nigerian pidgin (henceforth referred to as NP) based on the minimalist program, as well as elements of principle and parameters model of Chomsky's transformational grammar which is adopted as the theoretical model for this study. The paper is a pedagogical approach to the study of NP in the Niger Delta region of Nigeria where the language is creolised. In this study, a linguistic description of $w h$-interrogatives in English and NP focuses on wh-words/phrases that function as wh markers in the two languagesIt also deliberates on the derivation of $w h$-interrogatives in direct and embedded clauses with focus on the constraints in the respective languages. The paper also discusses the unique features of ná and nkợ as $w h$-forms in NP. Finally, the paper identifies the learning difficulties that a competent speaker of NP will encounter while learning English $w h$-interrogatives as a second language learner. This pedagogical approach is more pragmatic than the present repressive one where pupils and students are discouraged from communicating in NP.

\section{Theoretical Framework and Methodology}

The theoretical model adopted for the study is the minimalist program, as well as model of Chomsky's transformational grammar (Chomsky, 1995b). The main reason for the adoption of the theoretical framework is the fact that the data collected for the study is germane to the model's analysis.

Data for the two languages are collected from different sources. First, data were sourced from postgraduate/ undergraduate students of English and from competent speakers of NP in Warri, Effurun and Sapele who speak the language as a creolised form. Second, the researcher generated data largely through introspection since he is multilingual in English, NP, Urhobo, an indigenous language spoken in Delta Central Senatorial district and Yoruba which is spoken in Western Nigeria. Finally, data for the two languages were also sourced from completed research works and published materials. The methodology adopted for data collection is the qualitative method and the orthography adopted for NP is the phonetically based linguistics type (Note 1). 


\section{Background: English Language, Nigerian Pidgin and Typological variation of wh-interrogatives}

The sub-topic that discussed under the background includes the followings: an overview of contrastive analysis, English language in Nigeria, Nigerian pidgin and pidgin and typological variation of wh -interrogatives. The background will illuminate the study.

The research focus in this paper comes from the field of contrastive analysis in second language analysis is second Dras (2009:1) sucking describe contrastive analysis hypothesis thus:

According to the contrastive analysis hypothesis formulated by Lado (1957), difficulties in acquiring a new (second) language are derived from the differences between the new language and the native (first) language of a language user. Amongst the frequently observed syntactic error types in non-native English which it has been acquired that are attributable to language transfer are subject-verb agreement, noun-number disagreement and misuse of determiners.

Since English language is now the property of the world, number numerous studies of different language pairs which focus on learning of English have been carried out while many of such studies have investigated the lexical and syntactical errors of speakers of European languages like French Russia Czech and Spanish learning English as a second languages learning English as a second languages.

The study of contrastive analysis has been bifurcated into the pre and post 1980 eras. Gast (2008:3) examines how the scope of this field of study differ in the two eras.

While contrastive analysis in the earlier stages focused on the linguistic system on the linguistic system i.e grammar and the lexicon ("Microlingistics in James 1980 term), in the 1980s and matter of language use discourse structure ('macro linguistics') came to the fore and new fields such as contrastive sociolinguistics (Hellinger and Ammon, 1996) cross-cultural pragmatics (Wierzbicka 1985, 1992) and contrastive rhetoric, (Connor 1996) emerged.

A basic weakness of contrastive analysis is that it focuses only on errors caused by the interference, (Abbas, 1995). In recent years, the popularity of contrastive analysis declined due to the lack of interest in the relevance of this field of study's input as a viable pedagogical tool. Although contrastive analysis is no more at the centre of applied linguistics stage "neither has it made it final exist", (Johnson 2000:7).

Nigeria is a complexly multilingual speech community and English is the country's official language and that of formal education. Schneider (2011:142) opines that "more than 500 languages are spoken in the country". English has a higher market value in Nigeria because of its economic importance as the language of upward socio-economic mobility. The advent and growth of English has been investigated by many scholars; for discussion, see (Banjo, 1996) and Akere (1995). Bamgbose (2002:33) evaluates the peculiar feature of Nigerian English thus:

Although Nigerian English is a variety of the English Language among world Englishes, standard Nigerian English has now undergone nativisation and indigenization since it is now a blend of British and Nigerian culture.

English is now the default language of ICT and Technology. Oyeleye (2005:4) aptly describes English as "both a consequence of and a contribution of globalization".

NP is the only pidgin spoken in Nigeria. NP is a member of West African Pidgin English (W.A.P.E.). W.A.P.E. has three varieties which are Nigerian Pidgin (NP), Ghanaian Pidgin (G.P) and Cameroonian Pidgin (CP). Elugbe (1995) notes that the three varieties are mutually intelligible. W.A.P.E. is a member of West African Pidgins and its three varieties are W.A.P.E. Sierra Leonian Krio and Liberian Kru (Finney, 2003). West African pidgins are members of the Atlantic group of English-based pidgins and creoles.

NP and English are the ethnically neutral languages in Nigeria. NP has a national spread especially in military and paramilitary formations in the country. Schneider (2011:142) underscores the importance of the two languages in Nigeria's linguistic ecology thus:

Certainly, English and pidgin are mostly second (or third etc) languages, acquired in addition to tribal and regional languages. 
Both have been found to increasingly become mother tongues of African children as well, however, English is becoming a first language primarily in educated families and in urban contexts, and pidgin in certain regions and amongst the less affluent. Strictly, pidgin is thus a creolising language.

NP is inferior to English because it is used mainly for informal communication and it lacks a standard orthography. Unlike English, it is not the language of upward socio-economic mobility. This is why derogatory names like broken English and bad English are ascribed to the language (Holm, 1988). In fact, the use of the language is discouraged in primary and secondary schools in the Niger Delta, where the language has creolized, and in Nigeria in general. Due to the close affinity between NP and the indigenous languages in terms of structure and function, NP can be aptly described as a neo-Nigerian language.

\subsection{Wh-Interrogatives in English}

$W h$-constituents in English are mainly simple lexical $w h$-words and they are exclusively used singly. However, there are also $b i$-lexical and multi-lexical $w h$-phrases in the language. Examples of single and $b i$-lexical operator expressions are shown in figure 1 below:

Figure 1. Operator Expressions

\section{A}

\section{Simple Lexical $w h$-words}

i) Who

ii) Where

iii) Where

iv) When

v) What

vi) Whose

\section{B}

\section{Bi-Lexical wh-phrases}

vii) Which place

viii) What time

ix) Which person

Below are sentences with simple $w h$-word and $b i$-lexical $w h$-phrase respectively.

1a. The rain will fall when?

b. When will the rain fall?

2a. The train arrived what time?

b. What time did the train arrive?

\subsection{Derivation of wh-Questions in English}

Two types of movement are involved in the derivation of $w h$-questions in English. They are head-to-head or Head movement and operator movement or O movement. Head-to-head movement involves what Radford (1996:106) calls "movement from head position to another".

The derivation of (1b) and (2b) above will be used as illustrative examples to describe the derivation of wh-questions in English. In (1b), for example, the auxiliary will moves from $\mathrm{Agr}^{0}$ to $\mathrm{C}^{0}$ of CP. Chomsky (1995b) gives justification, for head movement of will to COMP by stating that COMP in an interrogative clause is a strong head. He further adds that a strong head has to be filled. Radford (1997:108) buttresses Chomsky's (1995b) assertion when he adds that:

A strong COMP node has the power to lure an auxiliary from INFL (Agrs) to COMP thereby satisfying the requirement for a strong COMP to be filled.

When will is moved, it leaves a trace and the moved auxiliary is the antecedent of the trace. The moved constituent is the head and the trace is the foot, and both of them form a chain. So, will moves up to C-command its trace.

If on the other hand, there is no auxiliary to fill COMP, a dummy do is generated in Agr ${ }^{0}$ and raised to COMP to satisfy what Radford (1996:111) states is the requirement for a strong COMP to be filled. Radford concludes that:

Chomsky (1995) suggests that dummy do is only used as a last resort i.e. only where needed in order to satisfy some grammatical requirement which would not otherwise be satisfied. 
So, dummy do is used in $2 \mathrm{~b}$ above to enable strong COMP to be filled.

The extraposition of the $w h$-word from its position as the complement of the verb to spec-CP position is known as operator movement. Radford (2002:268) describes how and what time in (1a) and (2b) are preposed thus:

The preposed operator expressions are moved into some pre-head positions in $\mathrm{CP}$, given that specifiers are generally positioned before heads, so they occupy the specifier position with CP (= spec-CP).

The moved wh-question operator in $1 \mathrm{~b}$ for example, always leaves a co-indexed trace known and abbreviated as wh-trace. Camie (2007:321) formalized $w h$-movement thus:

\section{Wh-movement;}

Move a wh-phrase to the specifier of a $\mathrm{CP}$ to check a $[+\mathrm{WH}]$ feature in $\mathrm{C}^{\mathrm{O}}$

\subsection{Pied piping of bi-lexical and multi-lexical wh-phrases}

Although, single $w h$-phrases are commonly used in wh-phrases in English, there are also cases of bi-lexical and multilexical $w h$-phrases in the language. Below are some examples.

3a) which house was refurbished yesterday?

b) which place did the incident happen?

4a) what type of film will you watch tomorrow?

b) what means of transportation do you prefer?

What one notices from the examples above is that the entire hi-lexical wh-phrases in (3a \& b) and the multi-lexical wh-phrases in ( $4 \mathrm{a} \& \mathrm{~b})$ are preposed from their positions as the complement of the verb to its spec-CP position. The movement of the entire wh-phrase in each of the examples above, has been described as a case of pied piping (see Radford, 2002 and Carnie, 2007).

If the complements of the wh-determiner of $(5 \mathrm{a} \& \mathrm{~b})$ below and $(4 \mathrm{a} \& \mathrm{~b})$ above are not pied-piped along with the moved $w h$-operator, an ungrammatical $w h$-question will be derived as shown in (5a \& b) and ( $6 \mathrm{a} \& \mathrm{~b})$ below.

5a) *which was refurbished yesterday house?

b) *which did the incident happen place?

6a) *what will you watch tomorrow type of film?

b) * what do you prefer means of transport?

The reason why (5a \& b) and (6a \& b) are ungrammatical is due to what Radford (2002) calls violation of Chain Uniformity Principle. Chomsky (1995b) formalized

Chain Uniformity Principle thus:

\subsection{Chain Uniformity Principle}

A chain must be uniform with regard to phrase structure.

So, the only way a uniform chain can be formed in the examples above is for the entire phrase to be pied piped to evolve a uniformity of the head and the foot.

In English, there is however an exception to the pied piping of bi-lexical and multi-lexical wh-phrases and Chomsky (1995b) termed preposition stranding as an instance. In preposition stranding, it is possible to prepose only the wh-word while the preposition is left in-situ; yet, such derived wh-question is grammatical. Below are some examples.

7a) For whom did you buy the jewellery?

b) Who did you buy the jewellery for?

8a) To where did my brother travel?

b) Where did my brother travel to?

So, in (7a) and (8a), the preposition associated with the wh-phrase is pied piped along the wh-phrase to spec-CP in conformity with the Chain Uniformity Principle. On the other hand, the preposition is left in-situ while the wh-phrase 
is preposed to spec-CP in violation of Chain Uniformity Condition in (7b) and (8b). Despite the fact that (7b) and (8b) violated Chain Uniformity Condition, both examples are still grammatical.

\section{5 wh-Movement in Embedded Questions}

Mathews (1997:111) defines embedding as "the inclusion of one clause or sentence in another." This syntactic process occurs mainly in complex sentences. The illustrative examples of $w h$-questions that have been used in this paper are those of $w h$-questions in simple sentences. However, wh-movement also occurs in embedded clauses. In English, the two types of wh-movement imbedded questions are: one, the case of a wh-phrase which is proposed from the embedded clause to the matrix clause of the complex or insert sentence. It is also known as a direct question in an embedded clause. Two, the case where a wh-phrase is preposed from the complement of the verb of the embedded clause to spec-CP of the same clause. The derived wh-question from $w h$-movement of the latter is known as indirect $w h$-question.

In the case of the former, the $w h$-phrase moves from the complement of the verb of the insert clause in phases until it gets to the spec-CP of the matrix clause. The reason why the movement of the $w h$-phrase is not a single leap from the complement of the verb of the insert clause to the spec-CP of the matrix clause is because the wh-phrase passes two clausal boundaries. Below are some examples.

9a) Where is the house that was burnt yesterday?

b) Who is the man that stole the money?

The extraposition of the wh-phrase from the insert clause to spec-CP of the matrix clause is illustrated with the (9b) below.

1) Who is the man that stole the money?

$\left[\mathrm{CP}_{2}\right.$ Who $\mathrm{C}^{1}-\mathrm{C}$ is $[+\mathrm{WH}]$ [AgrSP---DP the man TP---AgroP-VP-V; $\left[\mathrm{CP}_{1}\right.$ that $\mathrm{C}^{1}-\mathrm{C}^{0}[-\mathrm{WH}][$ AgrsP

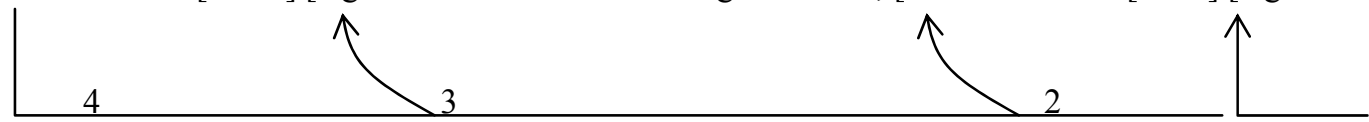

Agrs ${ }^{1}---\mathrm{TP}-$ AgrOP ---VP-V stole DP the money DP j[+WH] ]]]]]

As shown in the illustration above, who passes through three landing sites before it reaches its final landing site which is the spec-CP of the matrix clause. Between the clauses that the wh-phrase passes through, it leaves traces which Radford (2002) calls "intermediate traces."

In the case of $w h$-movement in indirect questions in embedded clauses, the landing site of the preposed wh-phrase is not the spec-CP of the matrix clause but the spec-CP of the embedded clause. The $w h$-phrase cannot be preposed to the spec-CP of the matrix clause because its COMP is [-WH] and if the wh-phrase is extraposed there, it cannot be checked by a $[-\mathrm{WH}]$ feature. So, the $w h$-phrase is preposed from the complement of the verb of the embedded clause to spec-CP of the embedded clause. The COMP of the embedded clause is [-WH]. The preposed wh-phrase will check the $[+\mathrm{WH}]$ feature of the embedded clause's COMP. Below are two examples of indirect wh-questions in embedded clauses.

10a) I wonder what killed the goat

b) I wonder when the train will arrive.

(10b) is illustrated below.

$\left[\mathrm{CP}_{2}\right.$--- C [-WH] [AgrSP---DP 1 TP---AgroP---VP--V wonder [CP-when

$\uparrow$

$\mathrm{C}[+\mathrm{WH}]$ [AgrsP DP the train TP T AgrOP--- Agro will - VP--V arrive Advpj ]]]]]

\subsection{Wh-Interrogations in NP}

NP bestrides the two cross linguistic variations of the $W h$-movement since it involves both the overt Wh-movement and it also occurs in-situ. When the $W h$-interrogative occurs in-situ in NP, it is like the case of Chinese/Japanese $W h$-question type. So, Wh-in-situ questions in NP are quite different from those of English which occur only in 
echoic questions. $W h$-in-situ questions in NP are, therefore, information seeking. Below are some examples of $W h$-questions formed through overt $W h$-movement and their $W h$-in-situ counterpart.

11a. Wetin yu bai?

What-thing you buy (past)?

What did you buy?

b. Yu bai wetin?

You buy + past what-thing?

You bought what?

In (11a), the $W h$-phrase in the question involves overt movement of the $W h$-phrase to clause initial position as in the English/Spanish type. In (11b) on the other hand, the Wh-phrase remains in-situ as in the Japanese/Chinese Wh-question type.

\subsection{Derivation of Wh-Movement in NP}

$W h$-interrogation in NP is derived through operator movement. This type of movement is also known as A-bar in the literature. The movement of the $W h$-phrase is always into a spec-CP position; what is more, the moved constituent always leaves a trace.

The constituents of Wh-elements in NP are briefly discussed below. In the mesolectal sociolect of Warri/Sapele variety of NP adopted for this study, Wh-constituents that always function as operator expressions are mostly bi-lexical; however, one simple lexical $W h$-constituent also exists in this sociolect as shown in figure 2.

Figure 2. Operator Expressions in NP

\begin{tabular}{|l|l|l|}
\hline $\mathbf{1}$ & $\begin{array}{l}\text { Operator expressions in the mesolectal } \\
\text { sociolect of NP }\end{array}$ & English Gloss \\
(i) & Which pẹsin & Which person - Who \\
(ii) & Wich taim & What time - When \\
(iii) & Wetin mek & What make - Why \\
(iv) & Wich ples & Which place - Where \\
(v) & Wusai & Which side/Where - locational positional \\
(vi) & Wetin & What-thing? What? \\
(vii) & Hu/h/im & Who/Him/Whose - positional \\
(viii) & Wie/wich ples & Where - locational \\
(ix) & Hau & How \\
\hline
\end{tabular}

Examples (i-vii) are bi-lexical while (ix) is a simple lexical $W h$-word. A recent trend among some speakers of the mesolectal sociolect is to use simple $W h$-constituent interchangeably with bi-lexical $W h$-phrase as shown in $12(\mathrm{a} \& \mathrm{~b})$ below.

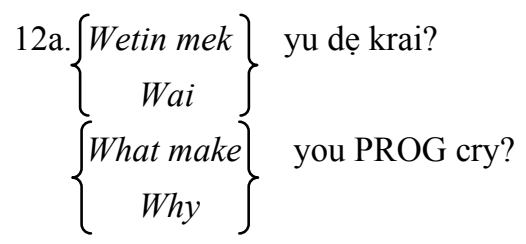

Why are you crying?

Elugbe and Omamor (1991) observe that hau (how) is a unique type of Wh-constituent in NP because it can function in both non-verbal and verbal clauses. They (1991:108) give the examples of the use of hau for greetings in non-verbal clauses thus:

13a. Hau nau - How are things?

b. Hau bọdi - How are you? 
(13a and b) above are actually covert verbal clauses that overtly appear as verbless ones because a copula (BE) is internally bound to $n a u$ and bodi respectively.

The impression created by Elugbe and Omamor (1991) above that the function of hau (how) is unique in NP is inaccurate. Pragmatically, hau (how) functions as an unritualised adjacency pair for greetings in both NP's substrate and superstrate languages. Below is an example each from Yoruba and Urhobo.

\section{Yoruba}

14a) Báwò ni

b. How it?

b.

rhobo

Mávọ

How

\section{English}

c. How are you?

How is your mum?

How are things? How is everything?

Hau (how) is also used to introduce overt verbal clauses in NP as shown in the examples below.

15a) Hau yu no im nem?

How you know his name?

How come you know his name?

b. Hau im tel yu di tori?

How he/she tell you the story?

How did he/she narrate the story to you?

Hau (how) is also used in serial verb constructions in NP as shown in $15 \mathrm{c}$ below:

c. Hau yu tek kil the snek?

How you kill + past the snake?

How did you manage to kill the snake?

Below are a set of examples of clauses with interrogative operators occurring in-situ and their positions after derivation.

16a) Yu de krai $\quad$ wetin mek?

You PROG cry what-thing make?

You are crying, why?

b. Wetin mek yu de krai?

What make you Prog cry?

Why are you crying?

In (16a), the interrogative operator appears in-situ while in (16b), it is extrapolated from its position as the complement of the verb and preposed to spec-CP position of the clause which is always unoccupied. Radford (2002:268) describes how Wetin mek (why) in (16a) is preposed thus:

The preposed operator expressions are moved into some pre-head positions in $C P$, given that specifiers are generally positioned before heads, so they occupy the specifier position with CP (= spec $-C P)$.

The moved $W h$-interrogative operator always leaves a co-indexed trace which is known and abbreviated as wh-traces.

Haegeman (1991:139) observes that what triggers Wh-movement is the feature (+WH) which always resides in the $\mathrm{C}^{\circ}$ of a Wh-sentence. She adds that "Wh-phrases move into the specifier of CP to check the Wh- feature." Based on Wh- movement discussed above, Carnie (2007:32) formalizes the operation thus:

\section{Wh-Movement}

Move a wh-phrase to the specifier of a CP to rheck a

$[+W H]$ feature in $C^{\circ}$. 


\subsection{Types of Wh-Interrogatives in NP}

Two types of Wh-interrogatives in NP are the direct and embedded ones. The internal constituents of each of the two sub-divisions identified above will be discussed in detail below.

\subsubsection{Single, Double and Multiple Wh-Phrases in Direct Questions}

In the mesolectal sociolect from which data was collected for this study, there is only one wh-lexical phrase that is exclusively used singly in NP. It is non decomposable Hau (how). Below is an example of Hau (how) in an NP clause.

17a. Hau yọ mama bọdi?

How BE mother body?

How is your mother's health?

In some contexts, single and double $W h$-phrases can be used interchangeably as shown in the example below:

b. $\left\{\begin{array}{c}\text { Wich pesin } \\ \mathrm{Hu}\end{array}\right\}$ kari [+ PAST] mai baisikul?

Who took my bicycle?

c. Wetin yu bai?

What thing you buy?

What did you buy?

Semantically, wetin collocates with (-HUMAN) features while wich pesin (which person) collocates with [+ HUMAN] objects.

Three bilexical $w h$-phrases still used exclusively bilexically in this socioletct are:

$\begin{array}{lllll}\text { 18a. Wich ples } & \text { b } & \text { Wich taim } & \text { c } & \text { Wetin } \\ \text { Which place } & & \text { What time } & \text { What-thing } \\ \text { Where } & \text { When } & \text { What }\end{array}$

Below are some examples:

19a. Wich taim dis rein go stọp?

Which time DET rain FUT stop?

When will this rain stop falling?

b. Wich ples yọ mama go?

Which place DET mother PAST + go?

Where did your mother go?

c. Wetin yu kari?

What-thing you carry?

What are you carrying?

There are also cases of multi-lexical $w h$-phrases functioning as operators of direct questions in $w h$-interrogatives. Below are some examples:

20a. Wich kaind mit yọ mama bai?

What kind meat ${ }^{\mathrm{DET}}$ mother PAST+buy?

What type of meat did your mother buy?

b. Hau meni shu $\left\{\begin{array}{c}\text { dem } \\ \mathrm{s}\end{array}\right\}$ yọ sista get?

How many shoe $\left\{\begin{array}{c}\text { them } \\ \mathrm{s}\end{array}\right\}$ do your sister get?

How many pairs of shoes do your sister have? 


\subsubsection{Pied Piping of Bi-Lexical and Multi-Lexical $W h$-Phrases (as in English - minimize)}

The preposing of the entire bi-lexical and multi-lexical $W h$-phrases from their position as the complement of the verb of the clause to its (Spec-CP) position has been described as cases of pied-piping in the literature (see Radford, 2002; Haegeman, 1991 and Carnie, 2007). If only the Wh- determiner is preposed and its complement is left in-situ, an ungrammatical structure will emanate as shown in (21b) below.

21a. Wich taim dis rein go stọp?

Which time DET rain FUT stop?

When will this rain stop falling?

* Wich dis rain go stop taim?

Which DET rain FUT stop time?

Which this rain will stop time?

22b. Which kaind mit yọ mama bai fọ maket?

What kind meat do PAST mother buy for market?

What type of meat did your mother buy in the market?

*b. Wich kaind yọ mama biai fọ maket mit?

What type your mother bought in the meat?

What type did your mother buy in the market of meat?

While (21a) is correct, (21b) is wrong because the complement of the $W h$-determiner is not pied piped along with the preposed $W h$-determiner. The reason why (21b) is ungrammatical is due to what Radford (2002) calls violation of the chain uniformity principle because the complement of the Wh-operator is not pied piped along with the Wh-determiner.

Pied piping of bi-lexical and multi-lexical $W h$-phrases in NP, however, has its exceptions. It is possible to generate grammatical sentences where only the $W h$-phrase is fronted while one or more grammatical constituents associated to the $W h$-phrase is left in-situ. Preposition stranding is a good example of the exception to the rule of pied piping in NP. In this case, a $W h$-phrase is moved while the preposition is left in-situ and the derived sentence is grammatical as shown in (22b) and (23b) below. However, if the Wh-phrase is moved, while pied piping the preposition associated to it, the sentence is still correct as shown (22a) and (23a) below. This is due to the fact that there is no one to one correspondence between the preposed Wh-operator and the trace it leaves behind as far as phrase structure rule is concerned.

23a. To wich pesin yu giv di moni?

To which person/whom you PAST give the money?

To whom did you give the money?

b. Wich pesin yu giv di mọni to?

Which person you PAST give the money to?

Which person/who did you give the money to?

24a. Fo wich wuman yu bai di moto?

For which woman you PAST buy the motor?

For which woman did you buy the car?

b. Which wuman yu bai di moto fọ?

Which woman you PAST buy the motor for?

Which woman did you buy the car for?

So in (23a) and (24a), the preposition associated with the $W h$-phrase is pied piped along with the $W h$-phrase to Spec-CP in conformity with the chain uniformity principle. In (23b) and (24b), on the other hand, the preposition is left in-situ while the Wh-phrase is moved to Spec-CP in violation of chain uniformity principle, however; the resulting sentences are grammatical. 


\subsection{Wh-In-Situ in Direct Questions and N'kộ as a Wh-in-Situ Marker in NP}

Wh-in-situ questions are also a part of direct Wh-questions in NP. Unlike in its superstrate language where Wh-in-situ questions are echoic, since they are meant to reaffirm an opinion the speaker already has about an issue, Wh-in-situ questions are information seeking in NP. So, Wh-in-situ questions and preposed Wh-questions are similar semantically. Pragmatically however, there is a dichotomy between these two set of Wh-questions since preposed Wh-questions are more emphatic than Wh-in-situ ones. Below are a few examples of Wh-in-situ questions in NP.

25a. Di rein go stop wich taim?

DET rain FUT stop which time?

The rain will stop when?/When will the rain stop?

b. Yọ mama go wich pies?

DET mother past + go which place?

Your mother went/travelled to where?/Where did your mother travel to?

c. Yu kil wetin?

You kill + past what thing

You killed what / what did you kill?

So, (25a-c) are not echoic; rather, they are information seeking. Wh-in-situ questions in NP bear a close affinity to those of its substrate languages. Ogbonna (2007-2008:73) corroborates this fact in his analysis of wh-questions in Igbo, a kwa language spoken in South Eastern Nigeria. He then gives these examples.

26a. İgàrà èbe?

You go-rv (past) where?

You did go where?

b. Èbe kà Igàrà tì?

What that you go rv (past)

Where did you go?

Based on (26a \& b) above, Ogbonna (2007-2008:72) concludes thus "therefore, in Igbo direct questions, the rule of Wh-movement is optional because failure to move the Wh-phrase does not affect meaning".

Nkộ is a Wh-in-situ marker in NP and it always occurs in clause final position. So, an ńkộ introduced Wh-question, like Wh-in-situ and its preposed Wh-phrase counterparts function as content or information seeking questions. Etymologically, ńkộ is derived from Yoruba, which is the main language spoken in Western Nigeria. Delta and Edo states were part of western region before 1963 when Midwest region was created. Below are two examples of ńkộ introduced Wh-questions.

27a. Mai mọni ńkộ

My money, what about/where?

What about/where is my money?

b. Yọ mama ńkộ?

Your mother, what about/how?

What about/How is your mother?

Pragmatically, there is a difference between a Wh-in-situ and an ńkộ introduced Wh-in-situ question in NP. An ńkộ introduced Wh-in-situ question is discourse linked because it cannot be the initial utterance in a piece of discourse. Other utterances must have preceded an ńkộ introduced Wh-in-situ question in NP. On the other hand, Wh-in-situ questions are not discourse linked because they can initiate a piece of discourse.

\subsection{Wh- Movement in Embedded Questions}

Embedding occurs mainly in complex sentences and Matthews (1997:111) defines this syntactic process as "the inclusion of one clause or sentence in another." Two types of Wh- movement are identified in embedded clauses in NP. They are; first, the case of a Wh- phrase which is preposed to the Spec-CP of the matrix clause in embedded clauses. This is known as direct questions in embedded clauses. In the case of Wh-movement of direct questions in 
embedded clauses, the Wh-phrases is preposed from the complement of the verb of the insert clause to the Spec-CP position of the matrix clause. Movement of the Wh-phrase is not a single leap because it passes two clausal boundaries before it gets to its final landing site. The moved Wh- phrase does not terminate at Spec-CP of the embedded clause because the $\mathrm{Wh}$ - feature in the $\mathrm{C}^{\circ}$ of the embedded clause is $-[\mathrm{WHj}]$. Due to this fact, the preposed Wh- phrase cannot be checked if it lands at the insert clause. However, the Spec-CP of the matrix clause is empty and its $\mathrm{C}^{\circ}$ is occupied by a $+\mathrm{WH}$ feature. So, the Spec-CP of the embedded clause is an escape hatch for it to pass through. Between the clauses that the Wh- phrase passes through, it leaves traces which Radford (2002) calls intermediate traces. Below is an example of the movement described above.

28. Wich peson you tink se tif the moni?

Wich person you think steal [Past] the money?

Who do you think stole the money?

An analysis of the movement described above is illustrated in (28b)

28b. $\mathrm{CP}_{1} \ldots \mathrm{C}[+\mathrm{WH}]$ wich pesin [AgrsP yu tink [CP ...C [-WH] se [AgrsP tif di moni i $\left.]\right]$ ?

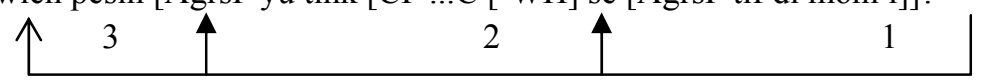

$\left[\mathrm{CP}_{1} \ldots \mathrm{C}[+\mathrm{WH}]\right.$ Which person [Agrsp you PAST think [CP ... C [-WI] COMP [Agrsp steal the money j]]] ?

Who do you think stole the money?

In the case of Wh-movement in indirect questions in embedded clauses, the landing site of the preposed Wh-phrase is always the Spec-CP of the embedded clause. This is due to the fact that the $\mathrm{C}^{\circ}$ of the embedded clause has [+WH] which the preposed wh-phrase checks; on the other hand, the $\mathrm{C}^{\circ}$ of the matrix clause is [-WH], so a Wh-phrase cannot be preposed to the spec-CP of the matrix clause because it cannot be checked by $\mathrm{C}^{\circ}[-\mathrm{WH}]$ feature. Below are two examples of indirect question in an embedded clause.

29a. A no sabi wich pesin Ese give di moni

I no know which pesin Ese give + past the money

I do not know/wonder who Ese gave the money

29b. $\left[\mathrm{CP}_{2}-\mathrm{C}\right] \mathrm{C}[-\mathrm{WH}]$ [AgrsP A no sabi $\left[\mathrm{CP}_{1}\right.$ wich pesin $\mathrm{C}[+\mathrm{WH}]-$ [AgrsP Ese giv di moni $\left.\left.\left.\left.\mathrm{j}\right]\right]\right]\right]$

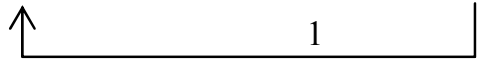

$\left[\mathrm{CP}_{2} \ldots \mathrm{C}\right] \mathrm{C}[-\mathrm{WH}]$ [Agrsp I not know [ $\mathrm{CP}_{1}$ which person $\mathrm{C}[+\mathrm{WH}]$ [Agrsp Ese past give the money j]]]]

I do not know /wonder whom Ese gave the money.

30a. A no sabi wetin mek pipul de rom

I no know what make people runtprog

I do not know why people are running

30b. $\left[\mathrm{CP}_{2}-\mathrm{C}\right] \mathrm{C}[-\mathrm{WH}]$ [AgrsP A no sabi $\left[\mathrm{CP}_{1} \mathrm{C}[+\mathrm{WH}]\right.$ [wetin mek [AgrsP ipul de rọn $\left.\left.\left.\left.\mathrm{j}\right]\right]\right]\right]$

$\left[\mathrm{CP}_{2}-\mathrm{C}\right] \mathrm{C}[-\mathrm{WH}]$ [AgrsP I wonder [CP C[+WHJ what make [AgrsP people Prog run j ]]]]

I wonder why people are running.

Unlike in its superstrate language where the feature (+WH) is strong, it is weak in NP due to the syntactic flexibility of the language. So, the relative clause in (20) can occur in either the matrix or embedded clause especially if we is deleted. This syntactic flexibility of NP is derived from its substrate languages and it further buttresses our opinion that Wh-interrogatives are derivatives of substrate languages.

\section{Discussion}

Our discussion focuses on the differences in the deviation of wh-interrogative in English and NP with a view into identifying the learning problems that a competent NP speaker will encounter while learning wh-interrogative as second language. The first difference is that while NP bestrides the two cross linguistic variations which are only overt movement wh-in-situ questions in English involves only echoic questions and not information seeking ones. So, the NP learner will be informed that the sentence below is echoic and not information seeking as the NP speaker erroneously believes as shown in the example below. 
31) you killed what?

Secondly while the derivation of wh-interrogatives in English involves both head to head and operation movements, that of NP deals with only operator movement. In the case English, if there is no auxiliary to fill a dummy do is generated in $\mathrm{Agro}^{\circ}$ which is meant to satisfy the requirement for a strong comp to be filled, such requirement is not necessary for the deviation of wh-interrogatives in NP. So, the sentences below illustrate the differences.

32) (a) What you buy?

(b) What do you buy?

The NP speaker will liter the ungrammatical sentence in (32a) until he is taught the imperative of the insertion of dummy $d o$ to drive the grammatical sentence in $(32 \mathrm{~b})$.

$32 b)$ Finally, NP is a syntactically flexible language, so; $[+\mathrm{WH})$ is week in NP. On other hand $(+\mathrm{WH})$ is strong in English. The syntactic flexibility of NP is attributable to its substrate languages.

\section{Conclusion}

The paper has attempted to gap in knowledge by drawing attention to the learning problems that is competent speaker of NP encounters while learning wh- interrogative in English as a second language. The recent change in the status of NP from a low prestige language to a high status one has increased the domain of use of the language. Since the speaking of NP cannot be extirpated from schools, a contrastive study of English and NP has become imperative.

The paper undertook a linguistic description of the two languages with a view into identifying the structural differences observed in wh-interrogative in the two languages. It was the structural differences that constituted the input of the paper's discussion with the learning problems that a competent NP speaker encounters while learning wh-interrogative in English.

Finally, the opines that the problem of language deficit in the English language by students in Niger Delta region will be minimized if English is taught through contrastive analysis. It is hoped that this paper will be of great benefit to pedagogists in the Niger Delta region where the language has creolised.

\section{References}

Apple, R. \& Mysken, P. (1987). Language contact and Bilingualism. London. Edward Arnold Publishers.

Agheyisi, R. N. (1971). West African Pidgin English: Simplification and simplicity. Ph.D Thesis, University of Stanford. University Microfilms, Ann. Arbor.

(1984). “The Standardization of Nigerian Pidgin English” English World Wide 5, No. 2(211-33).

Aikhionbare, M. O. (1981). Aspects of the syntax of Nigerian Pidgin English Relativization Focusing and Negation. M.A. Dissertation, University of Ilorin, Illorin Nigeria.

Barbay-Stoll, A. (1976). "Nigeria Pidgin English as a medium of literary Expression" African Bulletin. 27, 55-63.

(1975). "Some Aspects of Semantic Shifts in English Words in West African Pidgin English" Africana Bulletin, 29 (131-138).

Bamgbose, A. (1971). "The English Language in Nigeria" Spencer J. (ed) The English Language in West Africa. London: Longman.

Banjo, A. (1996). An Overview of the English Language in Nigeria. Ibadan. Ibadan University Press.

Chomsky, N. (1981). Lectures on Government and Binding. Foris Dordretch.

Connor, U. (1996). Contrastive rhetoric; Cross CulrueL Aspects of Second Language Writing. Cambridge. Cambridge University Press. http://dx.doi.org/10.1017/CBO9781139524599

(1995b). The Minimalist Program. M.I.T. Press, Cambridge Mass.

Esizimetor, D.O. (2004). "On the question of Standard Orthography for Nigerian Pidgin" in the Domestication of English In Nigeria. A festscript. In Honour of Professor Abiodun Adetugbo (eds) Dawonusi, S. and Babololu, E. A. Lagos. University of Lagos Press. (248-64).

Elugbe, B. (1995). "Nigerian Pidgin (Problems And Prospects,)" (eds) Bamgbose, A. et al. New Englishes: A West African Perspective. Ibadan, Nigeria, Monsuro Press.

Elugbe, B. \& Omamor. (1991). Nigerian Pidgin (Background and Prospects), Ibadan, Heinemann Educational Books. 
Faraclas, N.G. (1996). Nigeria Pidgin. New York. Routledge. http://dx.doi.org/10.4324/9780203192801

Finney, A. M. (2004). Substratal influence on the Morphosyntactic Properties of Krio. <http:/membersaol. com/afripalavaz/pidgin.html

Gast, Volker. (2008). “Contrastive Analysis” www.uni-Jenade/-mu65qev/papdf/ca.pfd. Retrieved, $5^{\text {th }}$ June, 2013.

Haegeman, L. (1991). Introduction to Government and Binding Theory, Oxford, Blackwell Publishers.

Haung, C.T.J. (1986). Logical Relations in Chinese and The Theory of Grammar, (Unpublished) PhD Dissertation, M.I.T

Hellinger, M. \& Ammon, U. (1996). Contrastive Sociolinguistics. Berlin; Mouton de Gruyter. http://dx.doi.org/10.1515/9783110811551

Holm, J. (1985). Pidgins and Creoles, (Vol. I), Cambridge, Cambridge University Press.

Jubril, M. (1995). "The Elaboration of the Functions of Nigerian Pidgin" (eds) Bamgbose, A. et al. New Englishes: A West African Perspective. Ibadan, Nigeria, Monsuro Press.

Li Y. N. A. (1992). "Indefinite wh in Mandarin Chinese. Journal of East Asian Linguistics 1, 125-56. http://dx.doi.org/10.1007/BF00130234

Matthew, P. H. (1997). Oxford Concise Dictionary of Linguistics. Oxford, Oxford University Press.

Mafeni, B.O.W. (1971). "Nigeria Pidgin” In The English Language in West Africa (ed) Spencer J. London. Longman. 95-112.

Marchese, L. \& Schnukal, A. (1982). "Nigerian Pidgin English" Journal of the Linguistics Association of Nigeria (213 - 219).

Mopoho, R. (1997). “Origins عl Definitions DU West African Pidgin English” Papers from the annual meetings of the Atlantic Provinces Linguistic Association 11-19.

Mafuwene, S.S. (1992). "West African pidgin English" In The Oxford Companion to the English language (ed) McArthur, iii. Oxford University Press.

Ogbonna, J. E. (2007-2008). "More on Wh- Movement in Igbo" ed. Taiwo, O. Research in African Languages and Linguistics. Ibadan, Hope Publications (63-82).

Oyeleye, L. (2005). "The New Linguistic order: A Critical Examination of the impact of Globalization on the English Language" M. Olateju and L. Oyeleye (eds) Perspectives on language and Nigerian Literature Ile-Ife Nigerian Obafemi Awolowo University Press.

Radford, A. (2002). Syntactic Theory and the Structure of English. Cambridge. Cambridge University Press.

Tonkin, E. (1971). "Some Costal Pidgins in West African". Social Anthropology and Linguistics (ed) by E.W. Ardener. London. Tacistock publications.

Walker. (1978a). Towards an Analysis of Nigerian Pidgin English" University of Leeds.

Wierzbicka, A. (1985). "Different Cultures, difference languages, different speech acts" Journal of Pragmatics. 9.2/3: $145-178$.

Wona, Sze-Meng, Jojo \& Dras, Mark. (2009). "Contrastive Analysis and Native language identification" www.alta.asn.au/evens/alta2009/pdALTA2009.07pdf. Retrieved $5^{\text {th }}$ June, 2013.

\section{Notes}

Note 1. Ezisimetor identifies three types of orthography that have been adopted for NP. They are early orthographies (EO) press orthographies (PO) and linguistic orthographies (LO). For a detailed discussion of linguistic orthographies, Ezisimetor DO, 'What Orthography for Nigerian Pidgin?" online at: http://www.ifra-niqeriaorg Naija (Retrieved in December 2010) 2010.

Note 2. Substrate influence on lexico-semantic processes is still common in pidgins and creoles that have close contacts with their substrate languages so, this feature is common in West African Pidgins (see Holm, 1998). 